\title{
Metabolomics Reveals Relationship between Plasma Inositols and Birth Weight: Possible Markers for Fetal Programming of Type 2 Diabetes
}

\author{
Pia Marlene Nissen, Caroline Nebel, Niels Oksbjerg, and Hanne Christine Bertram \\ Department of Food Science, Faculty of Agricultural Sciences, Research Centre Aarslev, Aarhus University, Kirstinebjergvej 10, \\ 5792 Aarslev, Denmark \\ Correspondence should be addressed to Hanne Christine Bertram, hannec.bertram@agrsci.dk
}

Received 19 March 2010; Revised 20 April 2010; Accepted 3 June 2010

Academic Editor: Mika Ala-Korpela

Copyright ( $) 2011$ Pia Marlene Nissen et al. This is an open access article distributed under the Creative Commons Attribution License, which permits unrestricted use, distribution, and reproduction in any medium, provided the original work is properly cited.

Epidemiological studies in man and with experimental animal models have shown that intrauterine growth restriction (IUGR) resulting in low birth weight is associated with higher risk of programming welfare diseases in later life. In the pig, severe IUGR occurs naturally and contribute substantially to a large intralitter variation in birth weight and may therefore be a good model for man. In the present paper the natural form of IUGR in pigs was studied close to term by nuclear magnetic resonance (NMR)based metabolomics. The NMR-based investigations revealed different metabolic profiles of plasma samples from low-birth weight (LW) and high-birth weight (HW) piglets, respectively, and differences were assigned to levels of glucose and myo-inositol. Further studies by GC-MS revealed that LW piglets had a significant higher concentration of myoinositol and D-chiro-inositol in plasma compared to larger littermates. Myo-inositol and D-chiro-inositol have been coupled with glucose intolerance and insulin resistance in adults, and the present paper therefore suggests that IUGR is related to impaired glucose metabolism during fetal development, which may cause type 2 diabetes in adulthood.

\section{Introduction}

It is well established that decreased growth during fetal development, leading to intrauterine growth retardation (IUGR) and consequently low birth weight, has crucial influence on health later in life, and is documented in population studies [1]. However, the relationship between birth weight and health later on in life cannot be described by a simple linear relationship but seems to be U-shaped [2]. The hypothesis that poor fetal growth increases the risk of developing metabolic disorder, like type 2 diabetes, coronary heart disease, elevated blood pressure, and obesity, in adult life, was first put forward by Hales and Barker[3]. Long-term epidemiological studies in humans have shown a relationship between birth weight and adult health, and later experimental studies mainly in animal models of IUGR have documented the original hypothesis[4]. The term fetal metabolic programming is generally accepted to describe the phenomenon of the long-term effects of a stimulus or insult during fetal development [4].

Several different experimental animal models have been used to study fetal metabolic programming. Accordingly, maternal metabolism during pregnancy has been manipulated, and the effects on the offspring have been investigated [5]. Maternal calorie restriction throughout gestation in guinea pigs has a negative effect on fetal growth, and postnatal glucose tolerance tests demonstrated a decreased glucose tolerance and increased fasting plasma insulin levels, suggesting insulin resistance [6]. Also maternal protein deprivation in rats showed an alteration in the glucose metabolism in the liver of the offspring [7]. Structural changes in the liver of offspring from protein deprived mothers were observed in the same study. Placental restriction induced by surgery caused reduced fetal growth, increased 
adiposity postnatal, and impaired glucose-stimulated insulin production in young sheep offspring [8]. Hyperinsulinemia produced in the fetal rhesus monkey during the last third of gestation indicated that insulin is important for fetal weight characteristics [9]. The cause of the naturally occurring IUGR is not fully understood, but decreased placental growth and efficiency for nutrient transfer seems to be important [10]. In litter-bearing species, like rat, mice, and pig, a naturally occurring form of IUGR are present. In these species, low birth weight animals have been coupled with retarded postnatal growth, hypertension and glucose intolerance [11]. Thus, studies in pigs showed that low birth weight is associated with glucose intolerance at 1 year of age [12]. It has been suggested that impairments in early cell development result in fetal malnutrition and predispose individuals to development of type 2 diabetes later in life [13]. An alternative hypothesis suggests that genetic variants predisposing the type 2 diabetes phenotype might also reduce birth weight by altering intrauterine insulin secretion or action [14] Other factors which likely explain fetal programming of adult health comprise changes in DNA methylation, increased apoptosis in the developing kidney, alterations in renal renin-angiotensin system activity, and increased fetal glucocorticoid exposure [15]. Nevertheless, even though the impact of fetal metabolic programming on adult health is well documented, the underlying mechanisms are poorly understood.

In the present study, the naturally occurring form of IUGR in the pig was used as an experimental model for fetal metabolic programming. The objective was to identify possible mechanisms during fetal development that can couple metabolism during fetal life with later development of the metabolic disorders.

\section{Materials and Methods}

2.1. Animals. Offspring from 6 Danish Landrace sows mated with one of 6 Danish Landrace boars were used in this study. After mating, the sows were reared under normal production conditions at the Faculty of Agricultural Sciences, Aarhus University, Denmark, until day 110 of gestation. Gestation length in pigs is 113-115 days. At day 110 of gestation sows were stunned using a captive bolt pistol, and immediately after bleeding the uterus was taken out. The umbilical cord of each fetus/piglet was cut and as much blood as possible was collected through the umbilical cord. Blood was used for production of plasma, which was kept at $-80^{\circ} \mathrm{C}$ until analysis was performed. Piglets were weighed and their position within the uterus horns recorded. Organs were weighed and some anatomical measures recorded. All procedures were carried out after permission from the Danish Animal Experiments Inspectorate.

2.2. Study Design. The data reported in this study is for a total of 24 piglets. Within each of the 6 litters, plasma from the 2 piglets with the lowest birth weight (LW) and the 2 piglets with the highest birth weight (HW) were analyzed by NMR and GC-MS methods as described in what follows.

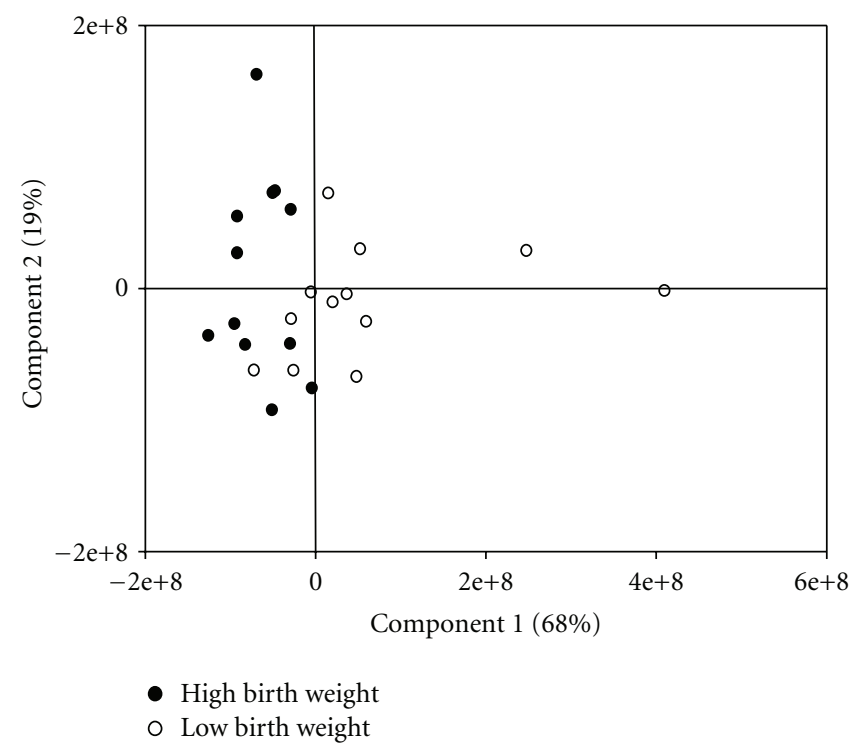

(a)

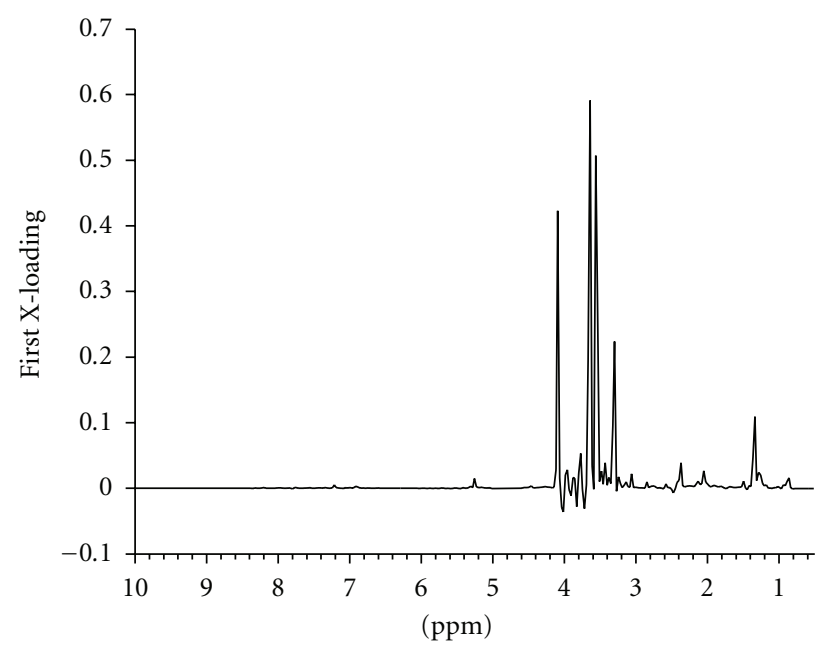

(b)

Figure 1: Differences in the ${ }^{1} \mathrm{H}$ NMR metabolite profile of plasma samples from low birth weight (LW) and high birth weight (HW) piglets. (a) PCA score plot showing the two first principal components for HW piglet samples (closed circles) and LW piglet samples (open circles). (b) Loading plot of first principal component.

2.3. NMR Measurements. The NMR measurements were performed at $310 \mathrm{~K}$ on a Bruker Avance III 600 spectrometer, operating at a ${ }^{1} \mathrm{H}$ frequency of $600.13 \mathrm{MHz}$, and equipped with a $5-\mathrm{mm}{ }^{1} \mathrm{H}$ TXI probe (Bruker BioSpin, Rheinstetten, Germany). Prior to the measurements, plasma samples were thawed and $400 \mu \mathrm{L}$ aliquots were mixed with $200 \mu \mathrm{l} \mathrm{D}_{2} \mathrm{O}$. Sodium trimethylsilyl-[2,2,3,3-2 $\left.{ }^{2} \mathrm{H}_{4}\right]$-1-propionate (TSP) was added as an internal chemical shift reference $(0.17 \mathrm{mg} / \mathrm{ml})$. ${ }^{1} \mathrm{H}$ NMR spectra of plasma samples were obtained using a Carr-Purcell-Meiboom-Gill (CPMG) delay added in order to attenuate broad signals from high-molecular-weight components. The total CPMG delay was $50 \mathrm{~ms}$. Water suppression 
TABLE 1: Anatomical characteristics of low birth weight (LW) and high birth weight (HW) piglets. LSMean values and standard errors of the LSMeans (SEM) are given.

\begin{tabular}{|c|c|c|c|c|}
\hline Traits & LW & HW & SEM & $P$ \\
\hline No. of piglets & 12 & 12 & & \\
\hline No. of female piglets & 6 & 6 & & \\
\hline No. of male piglets & 6 & 6 & & \\
\hline Body weight, g & 687 & 1,179 & 0.05 & $<.001$ \\
\hline $\mathrm{CRL}, \mathrm{cm}^{*}$ & 21.7 & 26.3 & 0.058 & $<.001$ \\
\hline CRL/100 g body weight & 33.0 & 22.1 & 1.9 & $<.001$ \\
\hline Pancreas, g/100 g body & 1.03 & 1.04 & 0.06 & NS \\
\hline \multicolumn{5}{|l|}{ weight } \\
\hline Liver, g/100 g body weight & 29.1 & 32.2 & 1.3 & .052 \\
\hline
\end{tabular}

was achieved by irradiating the water peak during the relaxation delay of $3 \mathrm{~s}$. A total of 64 transients of $32 \mathrm{~K}$ data points spanning a spectral width of $17.36 \mathrm{ppm}$ were collected. An exponential line-broadening function of $0.3 \mathrm{~Hz}$ was applied to the free induction decay (FID) prior to Fourier transform (FT). All spectra were referenced to the TSP signal at $0.0 \mathrm{ppm}$. The spectra were subdivided into $0.026 \mathrm{ppm}$ integral regions and integrated, reducing each spectrum into 345 independent variables in the region $0.52-4.60$ and 5.02$10.0 \mathrm{ppm}$.

2.4. GC-MS Measurements. Prior to GC-MS measurements, $50 \mu \mathrm{l}$ plasma from each sample was extracted with $960 \mu \mathrm{l}$ of $\mathrm{MeOH}(8: 1 \mathrm{v} / \mathrm{v})$ and $100 \mu \mathrm{l}$ of $0.1 \mathrm{mg} / \mathrm{ml}$ D6 myo-inositol (Isotech) was added. The sample was then centrifuged at $14,000 \mathrm{~g}$ for $10 \mathrm{~min}$ at room tempature Thereafter $100 \mu \mathrm{l}$ supernatant was transferred to GC-vials, evaporated and derivatized with $30 \mu \mathrm{l}$ of metoxyamin in pyridine $(15 \mathrm{mg} / \mathrm{ml})$ for $90 \mathrm{~min}$ at $30^{\circ} \mathrm{C}$. The sample was then added to $30 \mu \mathrm{l}$ of MSTFA (1\% TMCS; PIERCE), vortexed and left for $30 \mathrm{~min}$ at $37^{\circ} \mathrm{C}$. Thereafter, $40 \mu \mathrm{l}$ of heptan was added and the sample was vortexed before GC-MS.

GC-MS was performed using an Agilent 7890 GCsystem with a CTC COMBI PAL autosampler coupled to a single quadrupole mass spectrometer (Agilent 5975). Gas chromatographic separation was performed using a $30 \mathrm{~m}$ * $250 \mu \mathrm{m}$ (i.d.) * $0.25 \mu \mathrm{m}$ film HP-5MS column (J \& W Scientific). A volume of $1 \mu \mathrm{l}$ derivatized extract was injected into the GC-MS using split mode 1:10 with a split flow of $12 \mathrm{ml} / \mathrm{min}$. The inlet temperature was $270^{\circ} \mathrm{C}$. Oven temperature was increased from an initial $70^{\circ} \mathrm{C}$ to $230^{\circ} \mathrm{C}(15$ ${ }^{\circ} \mathrm{C}$ per min) and thereafter from $230^{\circ} \mathrm{C}$ to $300^{\circ} \mathrm{C}\left(10^{\circ} \mathrm{C}\right.$ per $\mathrm{min})$. The run time was $21 \mathrm{~min}$. Helium 6.0 was used as a carrier gas at a flow rate of $1.2 \mathrm{ml} / \mathrm{min}$. The ion source and quadrupole temperatures were 230 and $150^{\circ} \mathrm{C}$, respectively. Chromatograms and mass spectra were evaluated using the chemstation E.02.00.493 software. Myo-inositol-C-d-d6 (Isotech) was used as an internal standard. D-(+)-chiroinositol (cas 643-12-9; Aldrich) and Myo-inositol (Fluka) was used to perform standard curves for each compound over the expected range relative to the internal standard. Semiquantitative concentrations of plasma myo-inositol and D-chiro-inositol were obtained against the standard curves.

2.5. Data Analysis and Statistics. Multivariate analysis of NMR data was performed using the Unscrambler software version 9.2 (Camo, Oslo, Norway). Principal component analysis (PCA) was applied to the centered data to explore any clustering behavior of the samples, and partial least square regression (PLS) was carried out using NMR spectra as $x$-variables and birth weight as $y$-variable. Martens' uncertainty test [16] was used to eliminate noisy variables, and all models were validated using full cross-validation [17].

Statistical analysis of GC-MS data and anatomical properties were performed using the SAS version 9.2 (SAS Institute Inc., Cary, NC, USA) using the MIXED procedure.

The MIXED model generalizes the standard linear model as follows:

$$
y=\mathrm{X} \beta+Z \gamma+\varepsilon
$$

In this expression, $y$ represents a vector of observed data, $\beta$ is an unknown vector of fixed-effects parameters with known design matrix $\mathrm{X}, \gamma$ is a vector of random-effects parameters with known design matrix $Z$, and $\varepsilon$ is an unknown random error vector whose elements are not required to be independent or homogeneous.

The model included the fixed effects of gender and birth weight group (LW or HW) and their interaction and sow as a random factor.

\section{Results}

3.1. Anatomical Properties of Piglets. The average birth weight of LW and HW piglets were 687 and 1,179 g, respectively $(P<.001$; Table 1$)$. Also the crown-rump-length (CRL) was measured and LW piglets had an average CRL of $21.7 \mathrm{~cm}$ whereas HW piglets had an average of $26.3 \mathrm{~cm}$. The proportional length of LW piglets was significantly higher 


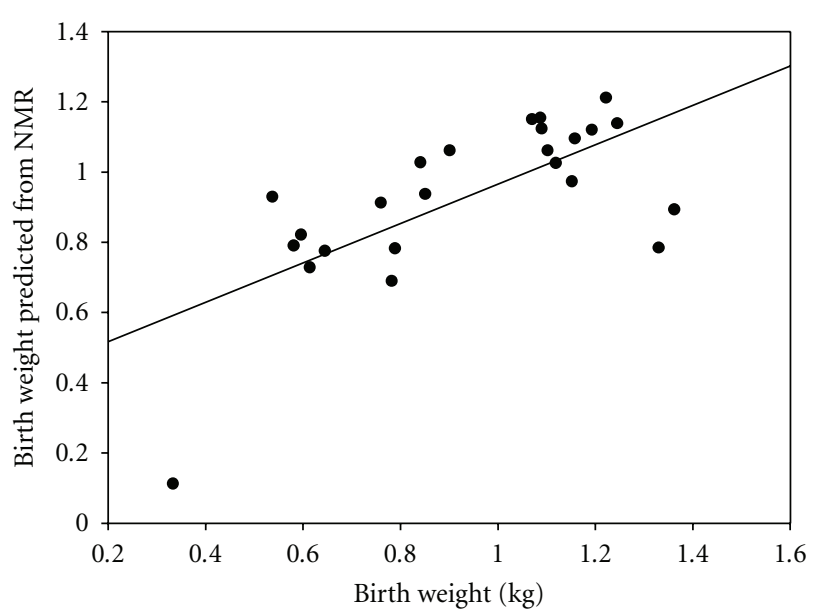

(a)

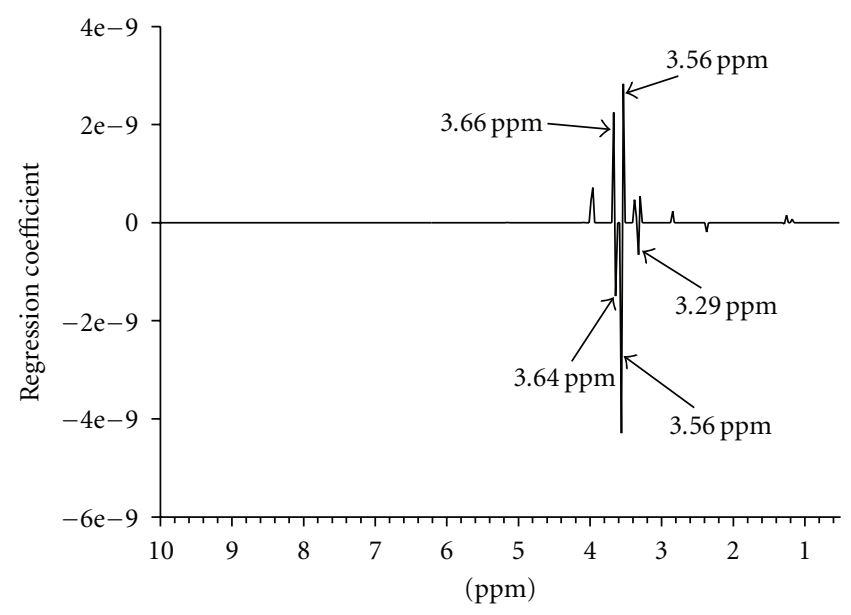

(b)

FIGURE 2: Prediction of birth weight by the ${ }^{1} \mathrm{H}$ NMR metabolite profile of plasma samples from low birth weight (LW) and high birth weight (HW) piglets. (a) Predicted versus measured birth weight from PLS regression with NMR-variables as $x$-variables and measured birth weight as $y$-variable. Values are given in $\mathrm{Kg}$. $R 2=$ 0.47 , Root mean squared error of prediction $=0.21 \mathrm{Kg}$. (b) The corresponding regression coefficients. The regression coefficients show the relationship between the NMR variables used as predictors for the birth weight. A positive coefficient shows a positive link with birth weight, and a negative coefficient shows a negative link. NMR variables with a small coefficient are negligible.

than of HW piglets $(P<.001$; Table 1$)$, indicating that the LW piglets were very thin. This is a trait which is often recognized in IUGR subjects [2]. The extreme differences in size at birth were evident in the present study, where the variation in birth weight differed from $334 \mathrm{~g}$ to $1,453 \mathrm{~g}$ in one of the litters. This LW piglet had an extremely low birth weight, and in the animal science literature this extreme LW piglet is referred to as a runt [18-20].

In this study, pancreas and liver were weighed (Table 1). The relative weight $(\mathrm{g} / 100 \mathrm{~g}$ body weight) of pancreas did not differ between LW and HW piglets, but the relative weight of

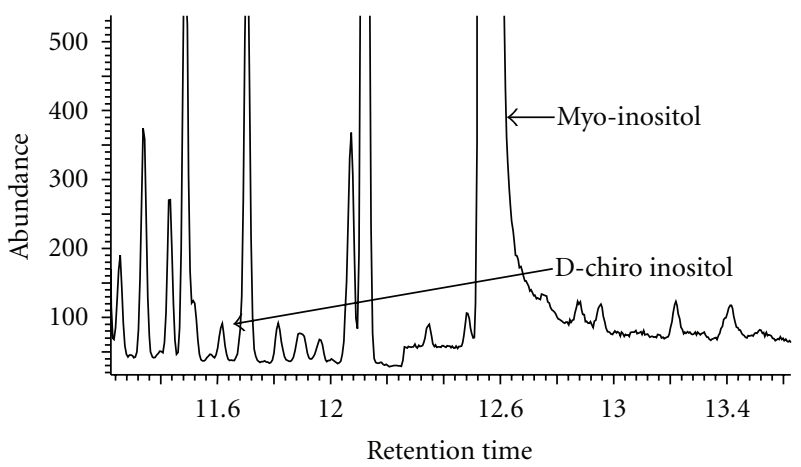

(a)

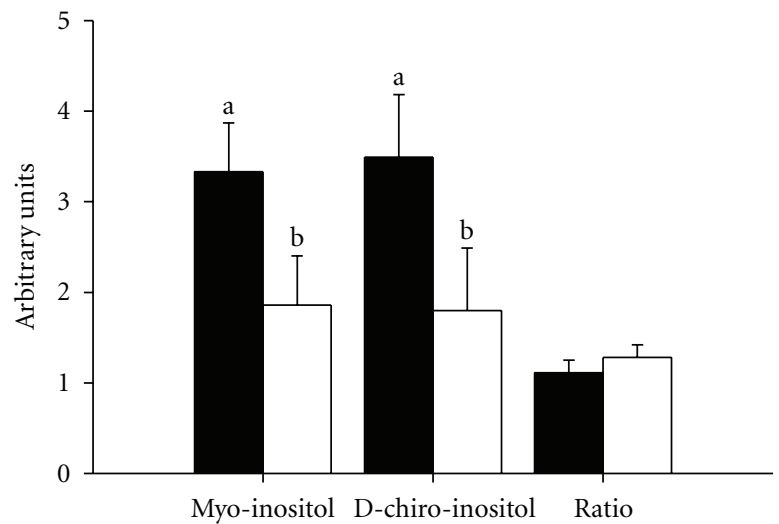

LW

$\sqsubset$ HW

(b)

Figure 3: Myo-inositol and D-chiro-inositol levels in plasma from low birth weight (LW) and high birth weight (HW) piglets. (a) GCMS spectra of a representative plasma sample. Peak at retention time 11.61 is D-chiro-inositol and peak at retention time 12.60 is myoinositol. The spectra reveal the large difference in concentration of D-chiro-inositol and myo-inositol in the plasma samples. (b) Arbitrary plasma inositol levels in LW and HW piglets, showing that LW piglets have a significantly higher plasma concentration of both myo- and D-chiro-inositol than HW piglets at birth. Each bar represents the LSMeans of 12 piglets \pm SEM. ab, $P<.05$. Bars named ratio is representing the ratio between $\mathrm{D}$-chiro-inositol and myo-inositol.

the liver tended $(P=.052)$ to be higher in HW than in LW piglets $(32.2 \mathrm{v} 29.1 \mathrm{~g} / 100 \mathrm{~g}$ body weight, resp.).

3.2. NMR Metabolomics. To investigate the early consequences of IUGR and possible relation with later development of adult health, a metabolomic approach was applied to plasma samples from LW and HW piglets by ${ }^{1} \mathrm{H}$ NMR spectroscopy. Principal component analysis (PCA), which is an unsupervised method, was performed on the preprocessed ${ }^{1} \mathrm{H}$ NMR spectra. The resulting plot of score 1 versus score 2 for mean-centered data shows a clear separation of plasma samples from LW and HW piglets, respectively, (Figure 1(a)). The corresponding X-loadings for the first component reveal that signals at 3.29, 3.56, 


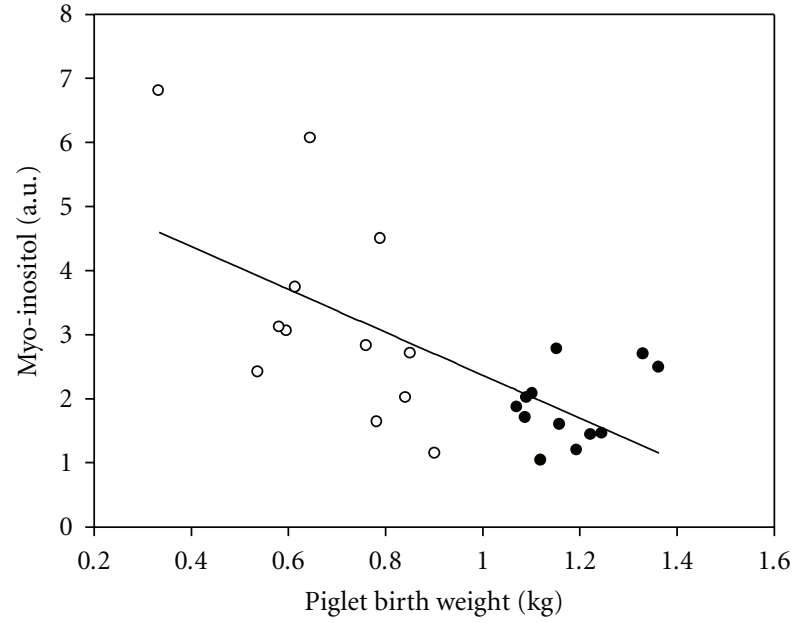

(a)

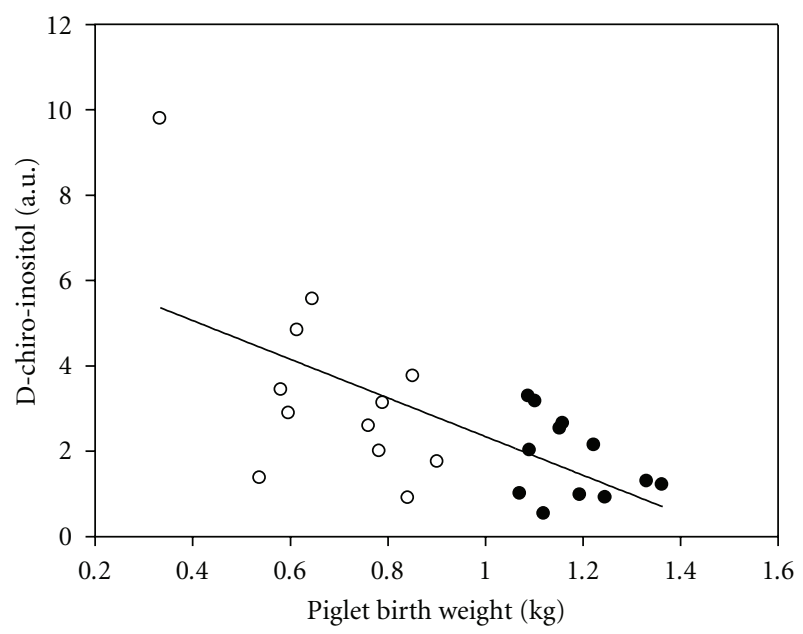

(b)

FIGURE 4: Relationship between piglet birth weight and (a) plasma myo-inositol and (b) plasma D-chiro-inositol. For both inositols a negative relationship (linear regression) exists between the plasma inositol concentration and piglet birth weight. $R^{2}=0.43$ for myoinositol; $R^{2}=0.42$ for D-chiro-inositol. Each point represents a single piglet.

and $3.64 \mathrm{ppm}$ are determining the position of samples along the first score, and thereby clearly dominate in the differentiation between LW and HW piglets (Figure 1(b)). These chemical shift values are equivalent with reference values for myo-inositol [21]. For a further investigation of the relationship between the ${ }^{1} \mathrm{H}$ NMR metabolite profiles and birth weight of the piglets, partial least squares (PLS) regression was carried out with NMR spectra as $X$-variables and birth weight as $y$-variable, which established a clear correlation $\left(R^{2}=0.47\right)$ (Figure $\left.2(\mathrm{a})\right)$. Analysis of the PLS model's regression coefficients reveals that intensities of signals at 3.53 and $3.66 \mathrm{ppm}$ are positively correlated to birth weight (Figure 2(b)), and these signals are tentatively assigned to glucose. In addition, the regression coefficients disclose that NMR variables at 3.30, 3.56, and $3.64 \mathrm{ppm}$, which are equivalent with reference values for myo-inositol
[21], contribute to the correlation between the ${ }^{1} \mathrm{H}$ NMR metabolite profiles and birth weight of the piglets, as the intensity of these are negatively correlated with birth weight.

3.3. Plasma Inositol Concentrations. In order to verify that the found effect could be ascribed to a higher myo-inositol in LW piglets, semi-quantitative plasma myo-inositol concentrations were determined together with semi-quantitative plasma concentrations of D-chiro-inositol by GC-MS. The LW piglets in the present study had a significant higher plasma concentration of both myo-inositol $(P<.01)$ and D-chiro-inositol $(P<.05)$ than HW piglets, whereas the myo-/D-chiro-inositol ratio did not differ between LW and HW piglets (Figure 3(b)). Also it can be seen from Figure 3(a) that the plasma level of myo-inositol is much higher than the level of D-chiro-inositol.

3.4. Correlations between Plasma Inositol Concentrations and Piglet Birth Weight. The above shown results verify that LW piglets have a higher plasma concentration of both myo-inositol and D-chiro-inositol than HW piglets. In this study, piglets from 6 litters have been examined but the variation in birth weight within each litter differs between litters. Thus, in some litters the LW piglets are not extremely small and may be more in the category of average weigh piglets in other litters. We therefore tested the correlation between piglet birth weight and both myo-inositol and Dchiro-inositol (Figure 4). These results verify that there is a negative correlation between piglet birth weight and myoinositol $\left(R^{2}=0.43\right)$ and D-chiro-inositol $\left(R^{2}=0.42\right)$ plasma concentrations. It can also be seen in Figure 4 that the variation in the plasma concentration of each compound seems to be higher in the LW piglets compared to the HW piglets. The extreme LW piglet also has a much higher concentration of myo-inositol and especially of D-chiroinositol compared to the other LW and HW piglets.

\section{Discussion}

In the present study we used the naturally occurring form of IUGR that exists in pigs to study the influences of IUGR on the plasma metabolomic. Even though pigs are a litterbearing species (9-14 piglets/litter) they seem to be a good model for human IUGR as there is increasing evidence that low birth weight pigs develop the same metabolic changes in relation to hypertension, obesity and type 2 diabetes as seen in human IUGR $[11,12,22]$. Thus, pigs are considered an excellent model for studying fetal metabolic programming and the adult consequences of IUGR.

In the present study, the 2 piglets with the lowest (LW) and the 2 piglets with the highest (HW) birth weight within each of 6 litters were studied in order to select pigs that had been subjected to IUGR (LW) and compared with pigs expected to have a normal nutrient supply during fetal development (HW). Piglets were taken from the uterus at day 110 of gestation (gestation length in sows is 113-115 days) in order to study piglets close to birth, but at the same time 
ensuring that the piglets did not suckle and thereby ingest food.

A fuel-mediated teratogonesis has been proposed [23]. Thus, fetal islets, fetal fat stores, fetal muscles, and a large range of other cells may be altered mediated by changes in fetal fuels [23]. Accordingly, the organs of IUGR subjects may have a disproportionate growth compared to normal subject, where for example, the weight of pancreas and liver relative to whole body weight is lower in protein-restricted subjects [24]. The disproportional growth of body length (CRL) and liver in relation to body weight found in this study indicates that some tissues and organs are more affected by the IUGR than others, which may have long-term effects on postnatal growth and metabolism in adulthood.

The NMR-based metabolomic data in the present study shows that the plasma concentration of glucose is positively correlated with birth weight. Fetal plasma glucose originates mainly from transport across the placenta and the fetus is therefore highly dependent on delivery of glucose from the dam [10]. Possibly some gluconeogenesis takes place in fetal liver at the late part of gestation, and the lowglucose concentration in LW piglets in the present study thus indicates either a low maternal-fetal glucose gradient and/or decreased fetal gluconeogenesis. It is well recognized that the placental transport of nutrients to the fetus is of utmost importance for fetal growth, and that placental size and efficiency of nutrient transport is reduced in relation to IUGR $[10,25,26]$.

Intriguingly, the explorative NMR-based metabolomic investigation demonstrated differences in plasma myoinsotiol between piglets with high and low birth weight, respectively. These findings were confirmed by GC-MS measurements, which also showed a difference in D-chiroinositol between high and low birth weight, respectively. Since the relationship between birth weight and health seems to be U-shaped [2], it could be questioned if the group of high birth weight piglets is an appropriate reference group. However, comparison of NMR data from an intermediate birth weight group revealed that the LW pigs also had a higher plasma myo-insotiol level than the intermediate birth weight group (data not shown). Myo-inositol and Dchiro-inositol, which in the present study are negatively correlated to birth weight, have been related to glucose intolerance and type 2 diabetes in several studies [27-29]. Consequently, these metabolites are interesting candidates as markers for fetal programming of metabolic disease in adult life. Myo-inositol is synthesized from glucose and is the most abundant inositol in the body. D-chiro-inositol is either synthesized from myo-inositol by epimerization or obtained from the diet. Previous studies have shown that in subjects with noninsulin-dependent and insulindependent diabetes, urinary excretion of myo-inositol and D-chiro-inositol was higher than in normal subjects both in humans and rats $[27,30]$, whereas others have found a decreased D-chiro-inositol concentration in human urine $[29,31]$. Reports on plasma concentrations of myo- and Dchiro-inositol in relation to diabetes are sparse, but a higher plasma concentration of inositols in acute diabetic compared to normal or mild diabetic rats was found in one study
[32], whereas no differences were found in another study comparing normal patients with non-insulin-dependent and insulin-dependent diabetic patients [30].

Thus, while it remains unclear if myo-inositol and Dchiro-inositol are useful biomarkers in adults, the present study suggests that they act as biomarkers in newborns. D-chiro-inositol seems to inhibit glucose-stimulated insulin release [33], suggesting a negative feedback mechanism after insulin-stimulated inositol phosphoglycan synthesis. Consequences of the high concentration of D-chiro-inositol found in LW piglets in the present study could be deficiency of insulin during fetal development. This may leave the insulin-responsive tissues like muscle highly sensitive to insulin [34]. In fact, highly insulin-sensitive tissues have been found in a low-maternal protein model for IUGR [35]. It could therefore be speculated that in the longterm, this could cause development of glucose intolerance and insulin resistance, and low-insulin concentrations would also have an impact on growth[34]. Also, the high Dchiro-inositol found in LW piglets may be a mechanism to decrease the glucose uptake in insulin-sensitive tissues, through the negative feedback on insulin release, leaving the small amount of available glucose for the more important tissues/organs in relation to survival, like the brain and heart. The biological significance of myo-inositol is less well understood. Thus, the present study suggests that myo-inositol and/or D-chiro inositol is useful markers in newborns, however, the consequences of the high plasma myo-inositol and D-chiro-inositol in LW piglets is not clear.

\section{Conclusions}

The present study demonstrated a clear positive relationship between plasma glucose concentration and birth weight and a negative relationship between myo-inositol and D-chiroinositol plasma concentrations on the one hand and birth weight on the other hand in the naturally occurring pig model of IUGR. Our results show that low birth weight (LW) piglets have a significant higher concentration of both inositols in plasma compared to larger littermates. As Myoinositol and D-chiro-inositol have been coupled with glucose intolerance and insulin resistance in adults, the present study indicates that these metabolites could be novel biomarkers for fetal programming.

\section{Acknowledgments}

This paper was supported by the Danish Research Council through the project "Foetal metabolic programming: Effects of intrauterine nutrition on metabolism and health later in life" and the Danish Technology and Production Research Council through the project "Advances in food quality and nutrition research through implementation of metabolomic technologies". The authors also appreciate the technical assistance of Marianne Rasmussen during NMR measurements. The Danish Agriculture \& Food Council is acknowledged for delivering the gilts for the present study. 


\section{References}

[1] A. Forsdahl, "Living conditions in childhood and subsequent development of risk factors for arteriosclerotic heart. The cardiovascular survey in Finnmark 1974-75," Journal of Epidemiology and Community Health, vol. 32, no. 1, pp. 34-37, 1978.

[2] T. Harder, E. Rodekamp, K. Schellong, J. W. Dudenhausen, and A. Plagemann, "Birth weight and subsequent risk of type 2 diabetes: a meta-analysis," American Journal of Epidemiology, vol. 165, no. 8, pp. 849-857, 2007.

[3] C. N. Hales and D. J. P. Barker, "Type 2 (non-insulindependent) diabetes mellitus: the thrifty phenotype hypothesis," Diabetologia, vol. 35, no. 7, pp. 595-601, 1992.

[4] K. M. Godfrey and D. J. P. Barker, "Fetal nutrition and adult disease," American Journal of Clinical Nutrition, vol. 71, no. 5, pp. 1344S-1352S, 2000.

[5] L. Aerts and F. A. Van Assche, "Animal evidence for the transgenerational development of diabetes mellitus," International Journal of Biochemistry and Cell Biology, vol. 38, no. 5-6, pp. 894-903, 2006.

[6] K. L. Kind, P. M. Clifton, P. A. Grant et al., "Effect of maternal feed restriction during pregnancy on glucose tolerance in the adult guinea pig," American Journal of Physiology, vol. 284, no. 1, pp. R140-R152, 2003.

[7] S. P. Burns, M. Desai, R. D. Cohen et al., "Gluconeogenesis, glucose handling, and structural changes in livers of the adult offspring of rats partially deprived of protein during pregnancy and lactation," The Journal of Clinical Investigation, vol. 100, no. 7, pp. 1768-1774, 1997.

[8] M. J. De Blasio, K. L. Gatford, I. C. McMillen, J. S. Robinson, and J. A. Owens, "Placental restriction of fetal growth increases insulin action, growth, and adiposity in the young lamb," Endocrinology, vol. 148, no. 3, pp. 1350-1358, 2007.

[9] J. B. Susa, C. Neave, P. Sehgal, D. B. Singer, W. P. Zeller, and R. Schwartz, "Chronic hyperinsulinemia in the fetal rhesus monkey. Effects of physiologic hyperinsulinemia on fetal growth and composition," Diabetes, vol. 33, no. 7, pp. 656-660, 1984.

[10] I. Cetin and G. Alvino, "Intrauterine growth restriction: implications for placental metabolism and transport. A review," Placenta, vol. 30, pp. 77-82, 2009.

[11] A. L. Fowden and A. J. Forhead, "Endocrine mechanisms of intrauterine programming," Reproduction, vol. 127, no. 5, pp. 515-526, 2004.

[12] K. R. Poore and A. L. Fowden, "The effect of birth weight on glucose tolerance in pigs at 3 and 12 months of age," Diabetologia, vol. 45, no. 9, pp. 1247-1254, 2002.

[13] J. J. Meier, "Linking the genetics of type 2 diabetes with low birth weight: a role for prenatal islet maldevelopment?" Diabetes, vol. 58, no. 6, pp. 1255-1256, 2009.

[14] R. M. Freathy, A. J. Bennett, S. M. Ring et al., “Type 2 diabetes risk alleles are associated with reduced size at birth," Diabetes, vol. 58, no. 6, pp. 1428-1433, 2009.

[15] K. Zandi-Nejad, V. A. Luyckx, and B. M. Brenner, "Adult hypertension and kidney disease: the role of fetal programming," Hypertension, vol. 47, no. 3, pp. 502-508, 2006.

[16] H. A. Martens and P. Dardenne, "Validation and verification of regression in small data sets," Chemometrics and Intelligent Laboratory Systems, vol. 44, no. 1-2, pp. 99-121, 1998.

[17] H. Martens and M. Martens, "Modified Jack-knife estimation of parameter uncertainty in bilinear modelling by partial least squares regression (PLSR)," Food Quality and Preference, vol. 11, no. 1-2, pp. 5-16, 2000.
[18] S. E. Handel and N. C. Stickland, "Muscle cellularity and birth weight," Animal Production, vol. 44, pp. 311-317, 1987.

[19] S. E. Powell and E. D. Aberle, "Skeletal muscle and adipose tissue cellularity in runt and normal birth weight swine," Journal of Animal Science, vol. 52, no. 4, pp. 748-756, 1981.

[20] P. V. J. Hegarty and C. E. Allen, "Effect of pre-natal runting on the post-natal development of skeletal muscles in swine and rats," Journal of Animal Science, vol. 46, no. 6, pp. 1634-1640, 1978.

[21] J. C. Lindon, J. K. Nicholson, and J. R. Everett, "NMR spectroscopy of biofluids," Annual Reports NMR Spectroscopy, vol. 38, pp. 1-88, 1999.

[22] F. Gondret, L. Lefaucheur, H. Juin, I. Louveau, and B. Lebret, "Low birth weight is associated with enlarged muscle fiber area and impaired meat tenderness of the longissimus muscle in pigs," Journal of Animal Science, vol. 84, no. 1, pp. 93-103, 2006.

[23] N. Freinkel, "Banting Lecture 1980. Of pregnancy and progeny," Diabetes, vol. 29, no. 12, pp. 1023-1035, 1980.

[24] M. Desai, N. J. Crowther, A. Lucas, and C. N. Hales, "Organ-selective growth in the offspring of protein-restricted mothers," British Journal of Nutrition, vol. 76, no. 4, pp. 591603, 1996.

[25] C. B. Doherty, R. M. Lewis, A. Sharkey, and G. J. Burton, "Placental composition and surface area but not vascularization are altered by maternal protein restriction in the rat," Placenta, vol. 24, no. 1, pp. 34-38, 2003.

[26] K. L. Kind, J. A. Owens, J. S. Robinson et al., "Effect of restriction of placental growth on expression of IGFs in fetal sheep: relationship to fetal growth, circulating IGFs and binding proteins," Journal of Endocrinology, vol. 146, no. 1, pp. 23-34, 1995.

[27] J. M. Kawa, R. Przybylski, and C. G. Taylor, "Urinary chiroinositol and myo-inositol excretion is elevated in the diabetic $\mathrm{db} / \mathrm{db}$ mouse and streptozotocin diabetic rat," Experimental Biology and Medicine, vol. 228, no. 8, pp. 907-914, 2003.

[28] G. Sarashina, M. Yamakoshi, M. Noritake et al., "A study of urinary myo-inositol as a sensitive marker of glucose intolerance," Clinica Chimica Acta, vol. 344, no. 1-2, pp. 181$188,2004$.

[29] T.-S. Jung, J.-R. Hahm, J.-J. Kim et al., "Determination of urinary myo-/chiro-inositol ratios from Korean diabetes patients," Yonsei Medical Journal, vol. 46, no. 4, pp. 532-538, 2005.

[30] R. E. Ostlund Jr., J. B. McGill, I. Herskowitz, D. M. Kipnis, J. V. Santiago, and W. R. Sherman, "D-chiro-inositol metabolism in diabetes mellitus," Proceedings of the National Academy of Sciences of the United States of America, vol. 90, no. 21, pp. 9988-9992, 1993.

[31] I. Asplin, G. Galasko, and J. Larner, "Chiro-inositol deficiency and insulin resistance: a comparison of the chiro-inositoland the myo-inositol-containing insulin mediators isolated from urine, hemodialysate, and muscle of control and type II diabetic subjects," Proceedings of the National Academy of Sciences of the United States of America, vol. 90, no. 13, pp. 5924-5928, 1993.

[32] K. P. Palmano, P. H. Whiting, and J. N. Hawthorne, "Free and lipid myo-inositol in tissues from rats with acute and less severe streptozotocin-induced diabetes," Biochemical Journal, vol. 167, no. 1, pp. 229-235, 1977.

[33] J. Larner, "D-chiro-inositol-its functional role in insulin action and its deficit in insulin resistance," International Journal of Experimental Diabetes Research, vol. 3, no. 1, pp. 4760, 2002. 
[34] R. Bhandari, K. R. Juluri, A. C. Resnick, and S. H. Snyder, "Gene deletion of inositol hexakisphosphate kinase 1 reveals inositol pyrophosphate regulation of insulin secretion, growth, and spermiogenesis," Proceedings of the National Academy of Sciences of the United States of America, vol. 105, no. 7, pp. 2349-2353, 2008.

[35] M. Thamotharan, B.-C. Shin, D. T. Suddirikku, S. Thamotharan, M. Garg, and S. U. Devaskar, "GLUT4 expression and subcellular localization in the intrauterine growth-restricted adult rat female offspring," American Journal of Physiology, vol. 288, no. 5, pp. E935-E947, 2005. 

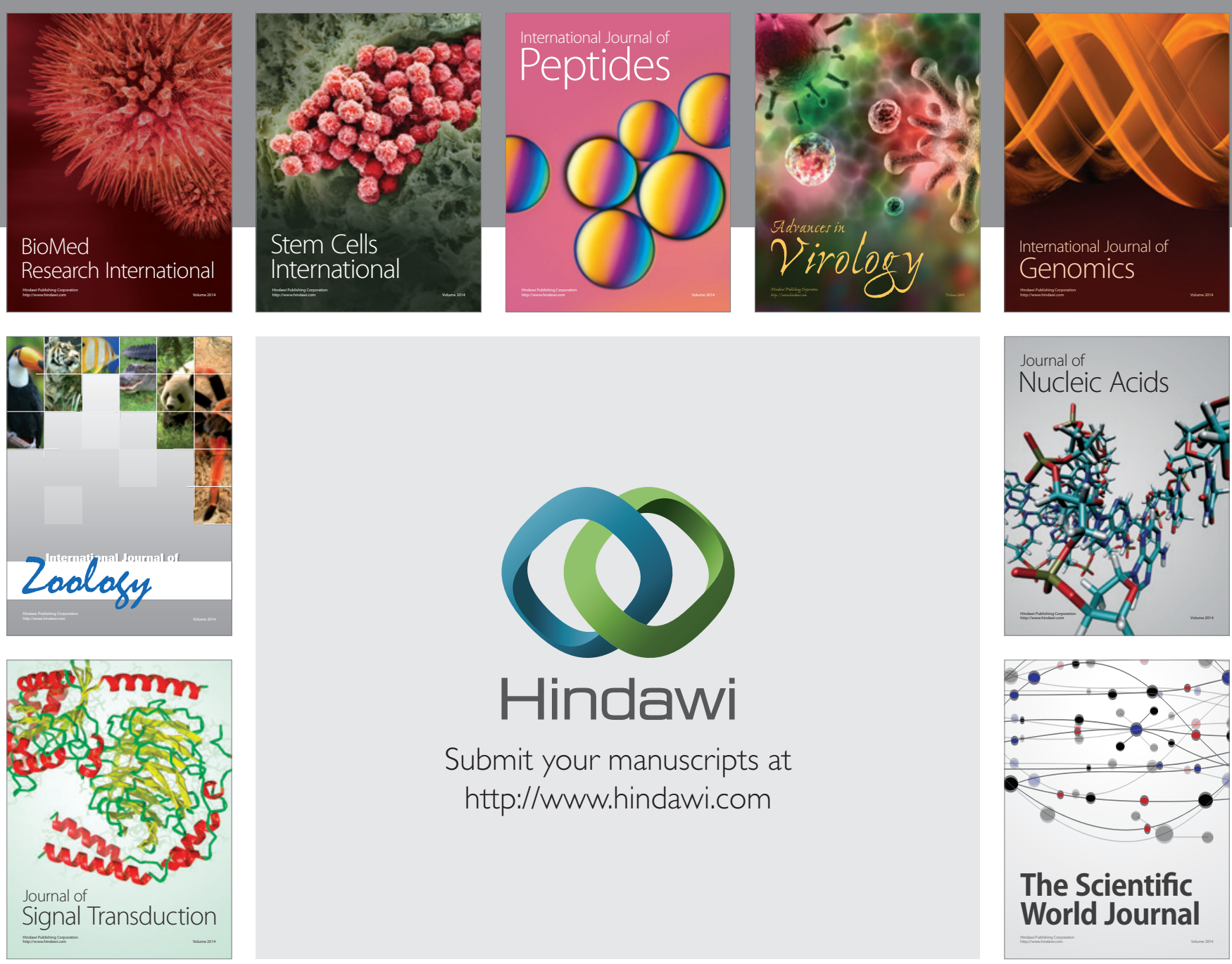

Submit your manuscripts at

http://www.hindawi.com
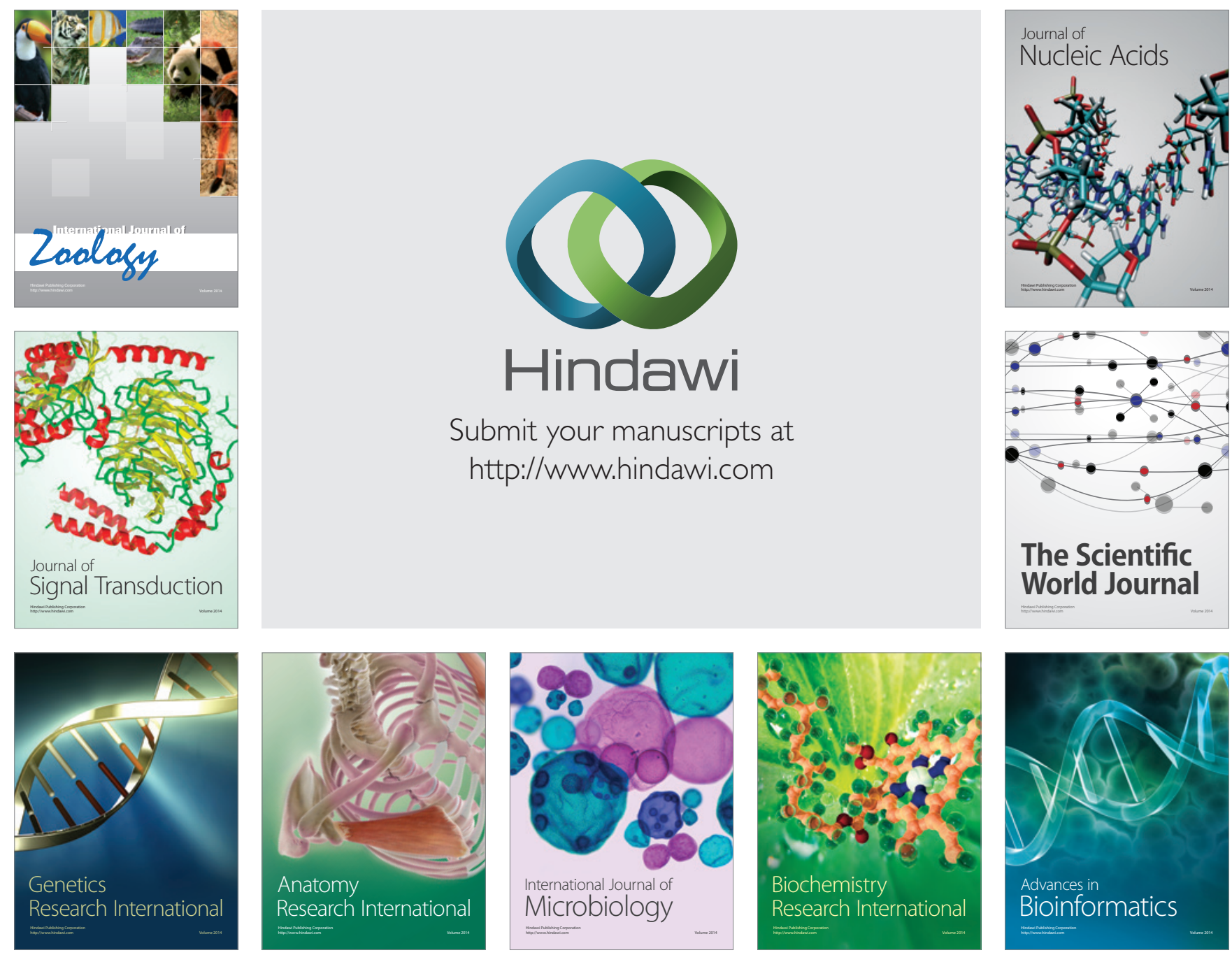

The Scientific World Journal
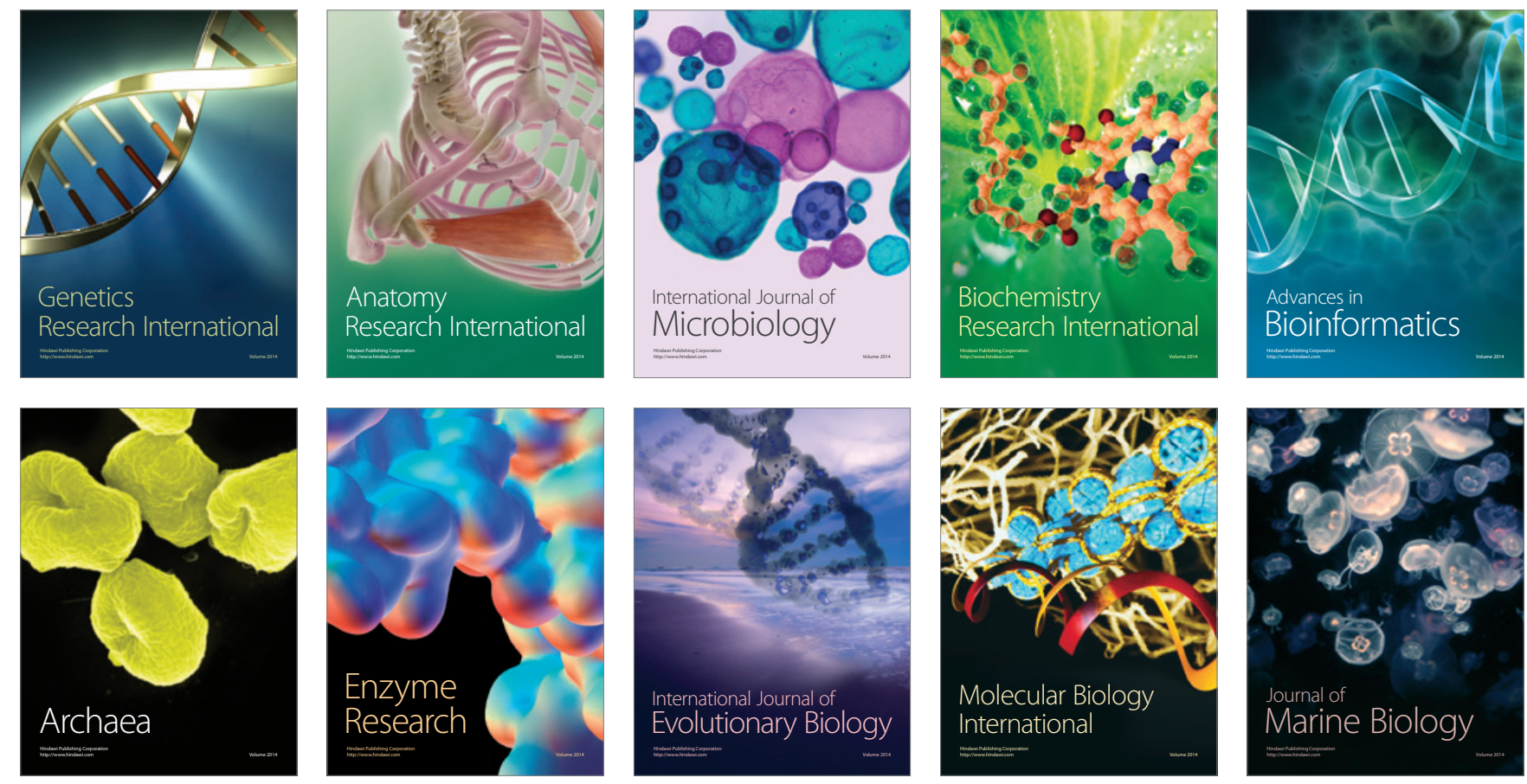